\title{
Acoger la vida para encender lo educativo. Una indagación narrativa de experiencias vividas por futuras docentes*
}

\author{
Julio Hizmeri Fernández \\ Universidad Católica de la Santísima Concepción, Concepción, \\ Chile \\ mail: jhizmeriducsc.cl \\ ORCID: https://orcid.org/0000-0003-3729-376X
}

\section{Roxana Hormazábal Fajardo}

Universidad Academia de Humanismo Cristiano, Santiago, Chile mail: rhormazabaldacademia.cl

ORCID: https://orcid.org/0000-0003-2163-1947

\author{
Alejandra Nocetti De la Barra \\ Universidad Católica de la Santísima Concepción, Concepción, \\ Chile \\ mail: anocettiducsc.cl \\ ORCID: https://orcid.org/0000-0003-2509-8051
}

\author{
Pilar Guzmán Córdoba \\ Universidad Academia de Humanismo Cristiano, Santiago, Chile \\ mail: pguzmandacademia.cl \\ ORCID: https://orcid.org/0000-0002-4755-9915
}

\section{RESUMEN}

El presente artículo da cuenta de experiencias vividas por profesoras en formación que colaboran en escuelas tanto municipales como particulares, y subvencionadas durante su práctica pedagógica (practicum) en contextos de pandemia por COVID-19. Los propósitos que han guiado este estudio son explorar las vivencias de enseñanza experimentadas por futuras/os profesoras/es y profundizar en las singularidades y sentidos educativos de dichas experiencias. Mediante una metodología de indagación narrativa, sostenida en relatos de experiencia, conversaciones narrativas y seminarios de profundización, nos adentramos en las relaciones educativas que se dan entre las y los estudiantes, los contenidos y las profesoras en formación. Los hallazgos nos permiten mostrar que, a pesar de las imposibilidades que devienen de un nuevo contexto de enseñanza que altera las formas de estar presente, con mediaciones que aparecen y otras que desaparecen, el tiempo de encuentro convoca más que nunca la necesidad de contar con la/el estudiante y su mundo, para que la enseñanza adquiera sentido manteniendo vivo el deseo de aprender $\mathrm{y}$, ciertamente, el de enseñar..

Palabras Clave: Indagación narrativa, experiencia, relación educativa, practicum, pandemia COVID-19.

\section{Embracing life to activate the educational act. A narrative inquiry about the experiences of future teachers.}

\section{ABSTRACT}

This article reports on the experiences of trainee teachers who collaborate in schools-public and private- during their teaching practice training (practicum) in the COVID-19 pandemic context. The purposes that have guided this study are to explore the teaching experiences of future teachers as well as to delve into the singularities and educational meanings of these experiences. By means of a narrative enquiry methodology based on accounts of real experiences, narrative conversations, and in-depth seminars, we delve into the educational relationships between students, contents, and trainee teachers. The findings show us that, despite the impossibilities arising from a new teaching context that alters the ways of being present-with new mediations that appear and others that disappear-the meeting time calls, more than ever, for the need to count on the students and their worlds, so that the educational journey keeps alive the desire to learn and, certainly, the desire to teach.

Keywords: Narrative Inquiry, experience, educational relationship, practicum, COVID-19 pandemic.

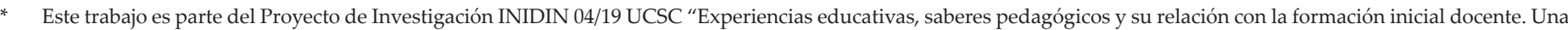
indagación narrativa de las prácticas docentes para la formación práctica".
}

ISSN: 0210-2773

DOI: https://doi.org/10.17811/rifie.50.3.2021.729-736 


\section{Introducción}

«Que nazca algo significa que la vida se ha hecho presente» (Hormazábal, 2016. p. 9)

\section{La escuela, el tiempo de enseñanza y la relación educativa}

A dos semanas del primer caso de COVID-19, en Chile se decretó Estado de Catástrofe. Era marzo de 2020 y las clases recién iniciadas, eran interrumpidas, al menos, en su modalidad presencial. Como era de esperar, prontamente irrumpieron iniciativas para investigar los alcances del COVID-19 en la educación, circulando una gran cantidad de encuestas y cuestionarios que pretendían saber qué estaban desarrollando las escuelas para enfrentar la situación. Sabemos que el impacto de este virus ha sido significativo tanto en nuestras vidas en general como en nuestras vidas educativas, y en este escenario es natural que emerja el deseo de dotar de sentido a todo, reavivando discusiones siempre vigentes como la desigualdad educativa, las brechas digitales y tecnológicas, el retraso en el aprendizaje, el roído derecho a la educación, la urgente inversión en educación pública, los desafíos en la formación docente, entre otros (Flores y Swennen, 2020; Hargreaves, 2021; Ruiz, 2020). Todas, nos parece, rondan la preocupación sobre el impacto que ha generado el virus del COVID-19 en el recorrido educativo de niños, niñas y jóvenes como resultado del cierre de las escuelas, porque es bien sabido que quienes cuentan con recursos suficientes, mayor capital económico, cultural y social, lo sobrellevan mejor que aquellos que carecen de dichos recursos, y la crisis ha revelado cuán importante es la educación pública (Biesta, 2020).

Paradójicamente, esta imposibilidad de estar en las escuelas nos ha hecho recuperar su importancia y valorar su carácter insustituible. No aquella institución autoritaria que combina obsolescencia de formas y contenidos (Dussel, 2018), sino una escuela que proporciona a cada cual -independientemente de su historia, aptitud, talento o lugar en la sociedad-, el tiempo y el espacio para abandonar su entorno conocido. Una escuela que ofrece "tiempo libre", un tiempo no productivo, a quienes por su nacimiento y lugar en la sociedad no pueden reivindicarlo. Un tiempo de fuga del sometimiento a las determinaciones del hacer, como una suspensión del tiempo para profanar lo instituido (Larrosa, 2018; Masschelein y Simons, 2014; Simons y Masschelein, 2018).

Y es verdad, la pandemia ha alterado la "domiciliación" de lo escolar (Dussel, 2020), los espacios y las modalidades de enseñanza, y las pedagogías pandémicas han salido a afrontar las consecuencias (Williamson, Enyon y Potter, 2020). Sin embargo, un llamado generalizado desde la institucionalidad es a no "perder el tiempo" - que se traduce como un control del tiempo, aunque ahora en el espacio doméstico - , y se apunta a priorizar aquellos conocimientos considerados imprescindibles para continuar con el proceso formativo de niños, niñas y jóvenes del país. Sabemos que el conocimiento es tratado como un bien económico y existe una jerarquía que la escuela reproduce sin apenas dudarlo (Masschelein y Simons, 2014) y la enseñanza autoritaria aspira a dirigir la atención de los estudiantes y mantener un control sobre lo que hacen (Biesta, 2020).

En el fondo, se ha producido una ruptura con las maneras tradicionales de abordar la enseñanza a propósito del distanciamiento físico: la no presencialidad. Aquella imagen en que estudiantes se hallan frente a maestras/os o profesores/as en un aula siempre nos ha parecido la escena más ajustada a la representación de la enseñanza. Y, si bien la educación a distancia se viene desarrollando desde hace décadas, la mayoría de los sistemas de educación aún están basados en la presencialidad, especialmente en el ámbito escolar.

Hoy, cuando la presencialidad es reemplazada por la modalidad a distancia mediante el uso de dispositivos tecnológicos, todo parece digno de simplificarse, reducir los intercambios, controlar los contenidos y gestionar el tiempo. Bajo esta idea de enseñanza deviene una pedagogía embrutecedora y la lógica de transmisión directa de un saber que debe pasar a otro, lo que el alumno debe aprender y lo que el maestro le enseña (Rancière, 2010). Mas, cuando la experiencia educativa se enciende, se resiste a la simplificación, al desvanecimiento de la relación y del encuentro pedagógico, pues "sin la presencia del otro, la comunicación degenera en un intercambio acelerado de información. No entabla ninguna relación, solo una conexión" (Han, 2017, p. 59). Así, entre pantallas a oscuras y micrófonos silenciados, más que nunca se ha revalorado la relación educativa y el deseo de "hacernos presentes en lo que hacemos, esa relación cara-a-cara, en lo que enseñamos y en lo que aprendemos" (Bárcena, 2012, p. 54).

Si entendiéramos la educación como un proceso controlado y evaluable, el sujeto de la educación nunca aparecería (Bárcena y Mèlich, 2000). Los alumnos, sin embargo, aparecen. Participan, sienten, saben y comprenden algo en la medida en que se implican con sus experiencias, biografías, historias, lugares, contextos. A decir verdad, el sujeto precede al saber, los otros y las otras cuentan, y en ello estriba la dificultad de la empresa pedagógica embrutecedora y que los pedagogos terminen siendo "los aguafiestas de la simplificación rutinaria" (Meirieu, 2016, p. 15).

Finalmente, en un escenario de prisas y clases de emergencia (Silva-Peña, 2020), en que los sentimientos de inseguridad, melancolía e incertidumbre de los practicantes desaniman y ponen en duda el potencial formativo del practicum (González-Calvo, 2020), hemos comprendido que hay más tiempos que el tiempo reglado que mortifica la pasión, la búsqueda y la curiosidad (Di Bartolomeo, 1998). La relación educativa reclama atención y detención, suspender el tiempo lineal del currículum o de la hora de clase para abrirse al tiempo vital de la experiencia; pues, lo significativo en educación no va a la velocidad del reloj, sino al ritmo de lo que una experiencia puede resonar en nuestro interior (Hormazábal, 2016). Así, frente a un tiempo indiferente a la calidad de los acontecimientos, las relaciones educativas - aquellos vínculos que salvaguardan la alteridad (Arnaus y Piussi, 2010) - , redefinen la calidad de un tiempo abierto a la posibilidad de que algo pase y la vida se haga presente.

\section{Método}

\subsection{Indagar narrativamente la experiencia}

Fundamentalmente, hemos optado por la indagación narrativa en nuestro estudio porque se adecua a un enfoque de investigación centrado en la experiencia y en los saberes experienciales. Entendemos la indagación narrativa (narrative inquiry) (Clandinin, 2013; Clandinin y Connelly, 2000) como un modo de exploración profunda de las prácticas, para hacer visible y pensable las experiencias vividas y relatadas, dando lugar a nuevas versiones de lo vivido, abriendo la posibilidad de recorrer y profundizar en nuevos sentidos educativos y saberes. Orientadas/ os por los aportes de Clandinin (2013), Van Manen (2003), Contreras (2016a, 2017) nos movemos hacia el sentido pedagógico de las experiencias, comprendiendo las dimensiones educativas o formativas que rondan las vivencias y se entretejen en los relatos.

El proceso de práctica de nuestras estudiantes es un camino progresivo de transformación para llegar a ser profesoras/es y 
cada vivencia, cada etapa y cada contexto educativo en el que se van desarrollando, es vivido de manera singular, por tanto, hace nacer diferentes saberes pedagógicos. Como formadoras/es las acompañamos en este camino, pero no estamos en las escuelas con ellas, por lo que la escritura y los relatos que van haciendo de su proceso, además de las conversaciones en clases, nos van mostrando algo de lo que ocurre en las escuelas, en la relación con las niñas, niños y jóvenes. ¿Y qué es ese "algo" ?, como dice Contreras (2016b), es aquello que vale la pena contar acerca de la vida de las escuelas, de lo que atraviesa la relación viva entre estas profesoras en formación y sus alumnas/os, y de lo que emerge como creación propia de esa experiencia educativa.

\subsection{Contexto}

El estudio que presentamos es parte de un proyecto de investigación, puesto en marcha desde el 2019, que explora los procesos de práctica de futuras/os docentes de diversas especialidades: Biología y Ciencias Naturales, Educación General Básica y Lenguaje y Literatura, de dos universidades chilenas (una pública no estatal y una privada). En ambas, se trata de prácticas progresivas y finales que tienen diversos niveles de profundización e intervención en diversas escuelas (municipales, particulares y subvencionadas). A partir de nuestro rol de formadoras/ es-investigadoras/es vamos entretejiendo las experiencias que viven nuestras/os estudiantes. Y los relatos que presentamos corresponden a cuatro estudiantes de práctica (intermedia y profesional), cuyas pasantías en los centros educativos, producto de la pandemia por COVID-19, han estado caracterizadas por la modalidad a distancia mediada por dispositivos tecnológicos.

\subsection{La composición de los relatos}

Los cuatro relatos emergen de las experiencias vividas por estas futuras profesoras en sus clases en las escuelas. Nosotros/ as fuimos acompañando y ensanchando el tejido experiencial a partir de las historias escritas por ellas y que nos iban mostrando las relaciones educativas vividas. Para co-componer y pensar con las historias propias y ajenas (Contreras, Quiles-Fernández y Paredes, 2019), hemos recontado y escrito estos relatos que luego compartimos en el equipo de investigación a través de seminarios de profundización y encuentros conversacionales, para adentrarnos en el significado de la vivencia, despertar nuevas resonancias, abrir interrogantes y sentidos. Desde allí, y a través de nuevas aperturas, hemos explorado estos sentidos más allá de lo inmediatamente vivenciado para ganar profundidad (Van Manen, 2014). Una profundización que entendemos y experimentamos como un modo de sostener un pensar que acompaña al relato, entrando en él como una voz que reflexiona pedagógicamente al hilo de las historias (Quiles-Fernández, Hizmeri y Hormazábal-Fajardo, 2018), revelando nuevas versiones de lo vivido junto a un pensamiento educativo que los ensancha, rescribe y transforma.

\section{Narrando los hallazgos}

\subsection{Practicar la perplejidad}

¿Quién podría decir que este 2020 no fue un año singular? "Ha sido muy difícil y complejo para todos. Nadie nunca nos dijo las dificultades que nos presentaría este año, pero ¿quién realmente hubiera querido vivir este año si nos hubieran dicho lo que pasaría?". Esto escribía Yessenia - de tercero de pedagogía en educación básica-, finalizando su diario reflexivo de este año memorablemente di- ferente. Su pregunta me conecta con lo educativo como experiencia ante esta prueba planetaria de lo imprevisto.

Esta vez Yessenia tiene el desafío de la práctica con un segundo básico y escribe sobre la incertidumbre de enseñar en este escenario pandémico. La entiendo, pues, parece que nos perdimos. En la realidad abrumadora de repensar la escuela y lo educativo intempestivamente, sin poder ver claramente lo que teníamos al frente. Se nos encarnó la perplejidad. María Zambrano dice que “anda perplejo no el que no piensa sino el que no ve" (2012, p. 93), en ese sentido, las escuelas y las/os profesoras/es estuvieron pensando qué y cómo hacer que lo educativo siguiera vivo en medio de esta crisis; pero ha sido muy difícil ver TODO lo que ocurría y vernos todos/as (como estábamos acostumbradas/os). Yessenia vivía esa perplejidad desde diferentes sensaciones al saber que comenzaría su práctica en modalidad a distancia y por medio de la plataforma Zoom:

"Tengo miedo de no encajar, de no aportar lo suficiente, de no ser de ayuda, de que sea solo una carga para los profes... sé que el miedo en ocasiones es bueno, nos hace estar atentos a nuestras equivocaciones, igualmente nos hace recordar que seguimos vivos $y$ que estos miedos son necesarios, al igual que los errores que cometemos. ¿Cuánto más tenemos que saber para poder ser buenos en esta nueva modalidad?"

Su perplejidad viene acompañada de preguntas; muchas de ellas para intentar comprender cómo se aprende del y en el desconcierto, cómo avanzamos sin automatismos, cómo se enseña en la incertidumbre, especialmente, cuando se trata de la niñez que requiere cuidado, amor, ser vista. Yessenia estaba preparada para un escenario escolar distinto, una relación diferente con las niñas y niños... y nosotras también la preparábamos para esa experiencia presencial en que los cuerpos están ahí: visibles, palpables, descifrables.

Llegaría el día de la práctica en la única modalidad posible en medio de la pandemia: online.

"Me siento algo incómoda y rara, no sé cómo reaccionar o ponerme en las clases. Antes podía estar en un rincón esperando que pidieran mi ayuda o simplemente levantar la mano y hacer algunas recomendaciones en la sala de clases, ayudando un poco a la profe guía. Tenía la libertad de pasearme por la sala e ir viendo a cada niñola que necesitara ayuda. Ahora todo es tan diferente, no sé cómo posicionarme, no sé en qué ayudar, no puedo poner atención en todos los niños/as. Me cuesta concentrarme, ;me imagino cómo deben estar los/as niños/as! Los veo desconcentrados, mirando hacia al lado, escuchando lo que hablan sus familiares detrás de ellos. Hay un sinfin de cosas que hacen que una se sienta 'cero aporte' para estos acompañamientos..."

Ese choque con la realidad escolar puesta en una pantalla fue una fractura con esa idea de profesora que acostumbrábamos a acunar en la formación. En medio del desconcierto y del sinsentido generado por la decisión ministerial de "priorización curricular", Yessenia encontró algo que faltaba atender en la asignatura de Lenguaje, pues, reconoció algunos problemas que las/ os niños tenían con la puntuación al leer. ¿Para qué estaban esos signos ahí? Más que procurar el vertiginoso avance curricular, Yessenia se detuvo a darle sentido a esos signos y planificó una clase:

"Les explicaría el significado de cada signo y leeríamos un cuento corto con diferentes signos de puntuación, usando un semáforo para la lectura y jugando con los colores: el rojo, para los puntos y 
significaba que teníamos que parar; el amarillo, para las comas con una pausa pequeña y continuar; y el verde para seguir leyendo"

La clase cubriría esas necesidades detectadas, pues los signos de puntuación se corresponderían con las pausas y la entonación del lenguaje hablado. Sin embargo, a pesar de que la propuesta era coherente, algo sucedía mientras ocurría la clase:

"Durante el tiempo que dediqué a la explicación del contenido, sentí que se estaba haciendo aburrido todo, para ellos y para mí. Los niños estaban muy callados, no sabía si estaban entendiendo y me di cuenta que tampoco les había preguntado nada. Cuando llegó el momento de la actividad, en vez de hacerlo niño por niño, decidí que uno hiciera la lectura y, al llegar a un signo de puntuación, todos teníamos que gritar "ialto!, ipausa!". Fue divertido porque todos gritábamos, nos reíamos, se generó un desorden porque algunos gritaban después, ya que su internet era más lento. Pero de ahí en adelante sentí que estábamos todos en la clase y cuando les pregunté, habian entendido todo y lo habían disfrutado. Me sentí tan bien, tan yo, y de verdad sentí que estaba en el lugar indicado, haciendo lo que realmente quería hacer".

Yessenia percibe lo que pasa y se permite hacer cambios. Deja entrar la niñez: las risas y el juego de los 7 años que hacen que la clase se vuelva una experiencia para todos. Sin embargo, sigue preguntándose qué más hacer, cómo mejorar, cómo sería si hubiese conocido las caras de varios/as alumnas/os que no pudo ver durante su práctica. Hay cosas que Yessenia aún no puede ver, y en eso me siento reflejada. Este tiempo nos deja una serie de preguntas ¿cuándo se vuelve algo vivo el currículum? ¿qué necesitamos para que lo que hacemos tenga sentido en el momento preciso? Si la perplejidad no detiene el pensar sino la capacidad de ver, ¿significará que deberíamos reaprender a ver(nos) de verdad, a ver la escuela y lo que ocurre en ella de una forma más sensible, más situada en la pregunta como antesala de la reflexión para dar vida a lo nuevo, a la posibilidad, a la risa, al juego, a la esperanza?

\subsection{La huerta en casa: contradicciones que enseñan}

Hay historias que atrapan como la historia de Cindy, una estudiante de Pedagogía en Biología y Ciencias Naturales que está en su último año, y con quien comparto los temores de enfrentar las clases virtuales en el marco de una enseñanza signada por la pandemia provocada por el COVID-19.

Una de esas tardes en que los estudiantes relatan en clase lo que les ha ocurrido en su práctica pedagógica, Cindy nos contó su experiencia de la "Huerta en casa". Todo comenzó cuando le pidieron realizar una actividad "extracurricular" para "distraer" a las alumnas/os. La intención es "sacarlos" de la monotonía de clases virtuales. ¿Una huerta? Ella lo recuerda así:

"Ya me sentía tensa en esta práctica y, además, me imponen la tarea de hacer una huerta. Al inicio estaba demasiado enojada y me decía, no sé técnicas de huerta en casa, pero lamentablemente voy a tener que aprenderlo. Y, además, esto surge como una actividad extracurricular. La idea era ofrecer un distractor al estudiante para sacarlos del aprendizaje del aula virtual".

¿Una huerta para distraer a los alumnos y alumnas? ¿una actividad extracurricular? ¿acaso sólo distrae lo extracurricular? ¿el camino del currículum no permite desvíos? Claramente, Cindy se sentía ajena a huertas, a cultivos. Le tensiona alejarse de su empresa pedagógica, aunque no había vuelta que darle: debía aprenderlo.
Pero ¿cómo abordar algo nuevo sin desaferrarse de lo que sabe y siente que debe enseñar? ¿cómo articular la huerta con la materia que enseña? Había que empezar por lo "ajeno", aunque hay cosas que están más cerca de lo que creemos. Recuerda:

"Recurrí a mi mamá que tiene experiencia con un invernadero en el campo y yo le decía: -mamá, por favor, dime qué hiciste, cómo lo hiciste y mándame videos (...) Mientras ella me iba contando, yo iba pensando en algunos contenidos curriculares".

Lo aparentemente extracurricular se trenza con lo curricular de una manera más armoniosa de lo pensado. Su tensión era, quizás, no distraerse de los contenidos de la asignatura y, a través de la charla con su madre, Cindy pudo establecer, sin dificultad, relaciones con la materia e imaginar el proceso formativo. La clase quedó planeada.

Durante la clase, las explicaciones fueron sucediendo a las preguntas y las respuestas dando comienzo al trabajo hortelano. Las niñas y niños aprendían con entusiasmo: "Incorporé los contenidos del currículum en el tema de la huerta: requerimientos de las plantas, el tema del medio ambiente y manejo de residuos entre otros". Llegaba el momento de poner la semilla en la tierra cuando al otro lado de la pantalla apareció una voz inesperada. La abuelita de Cristian: "la semilla no tiene que estar tan abajo porque si no se ahoga", "no pongas la semilla tan abajo".

Escuchar la frase "la semilla no tiene que estar tan abajo porque si no se ahoga", quizás revivió la conversación con su madre antes de las clases y le confirmó la feliz conexión con ese saber vital que habita en aquellas casas del sur de Chile en que aún se cultivan huertos. Claramente, las articulaciones no eran sólo entre huertas y contenidos, sino que había algo más: una relación entre conocimientos y saberes experienciales.

"Cuando yo me abro a que otra comparta su experiencia, como fue el caso de la abuela, y le doy la interpretación teórica, me pasa que reconozco un aprendizaje más significativo en mis estudiantes, porque yo no tenía la experiencia sobre la huerta y la participación de la abuela me ayudó a explicar varios conceptos presentes en el currículum y tengo la certeza que mis estudiantes los aprendieron".

Cuando la abuela dice "no pongas la semilla tan abajo", las explicaciones sobre la disposición de agua, los nutrientes, la intensidad de la luz, se va entrelazando con un saber experiencial sobre la germinación para que la vida que tiene que nacer no se ahogue.

Es verdad que "el presente es más grande que lo que nuestro Yo nos dice, es a un tiempo necesidad y apertura" (Piussi, 2006, p. 17); es necesario acoger la complejidad de lo real para que se encuentren el deseo de enseñar y aprender en un inusitado diálogo entre saberes, donde que lo que se enseña no tiene porqué lidiar con los saberes que circulan en las casas (aquellos que habitan junto a la experiencia de madres y abuelas). En el encuentro de voces, conocimientos y saberes se generó una matriz curricular que alumbró el valor de saber experiencial y que avivó un aprendizaje que se mantuvo siempre a ras de suelo y no se ahogó en la abstracción.

Los alumnos disfrutaron de la clase, pero también "aprendieron conceptos que difícilmente van a olvidar", y que están cerca. Y siento que Cindy experimentó que, junto a las tensiones y contradicciones, pueden emerger otros modos de atender el saber disciplinar (Quiles-Fernández y Orozco Martínez, 2019), nacer encuentros formativos imprevistos y que, finalmente, la enseñanza de las ciencias puede girarse hacia el laboratorio de la vida. 


\subsection{Lo importante es la otra persona}

Yadhira siempre ha soñado con ser profesora. Durante su niñez en Perú jugaba a ser maestra, sus juguetes y peluches fueron sus primeros estudiantes. Aquella niña transmitía en sus clases lo que soñaba, lo que le habían contado y repetía lo que aprendía en la escuela. Ahora vive en Chile, cursa tercer año de pedagogía en educación básica y en esta práctica enfrenta un aula muy distinta a la imaginada en la niñez. Un espacio desconocido, distante, virtual, al que llega con miedo y ansiedad.

\begin{abstract}
"La presentación en el centro de práctica fue online. Es un espacio nuevo, las clases, los niños, un grupo que mezcla cuarto y quinto básico... todo nuevo, o sea, estoy fuera de mi zona de confort, salí de mi zona cálida. Tengo mucho miedo y mucha ansiedad, incluso desde antes de que me destinaran a esta escuela, ya que no sabía en qué lugar me tocaría, pues todo será virtual por esto de la pandemia, eso me complica infinitamente".
\end{abstract}

La virtualidad enfría su cuerpo y lo desconocido se acompaña de temor y ansiedad. La pandemia lo complica todo. Llega el primer día, se sienta frente a su computador y en la pantalla comienzan a aparecer uno a uno los niños:

"Llegaron 5 estudiantes. iTan pocos!, pensé. Estaba acostumbrada a tener mínimo 30. La mayoría dirá 'qué fácil', pero se equivocan, no es tan fácil como parece, los/as niños/as dialogan, hacen muchas preguntas, son muchas veces muy participativos. Entré a la sesión y también estaban los papás y mamás conectadas junto a ellos y ellas. Mi profe guía se sabía el nombre de casi toda la familia... y eso me dejó más sorprendida."

Yadhira está frente a la pantalla al igual que su profesora guía. "Lo que importa es la otra persona", le dice la profesora. Las palabras de la profesora se encuentran con sus emociones y le llevan a entender que lo importante aún se mantiene: fijarse en las niñas y niñas. Son palabras sencillas, verdaderas, cercanas a la vida, que le mueven a alterar su disposición original sobre el aula virtual y le invitan a apreciar el movimiento que en ella ocurre, a mirar a sus estudiantes, a escuchar sus preguntas, a oír diálogos. Comienza a despojarse de la ansiedad para disponerse a aprender, a enseñar, a crear, a explorar, a pensar y vivir ese cambio tan drástico de enseñar (Duschatzky, 2019).

Los sueños y juegos de infancia comienzan a transitar hacia este nuevo espacio. Y Yadhira se irá preparando para acompañar la enseñanza. Llega el momento de la primera intervención, planifica una actividad y antes de su clase envía el material a la profesora guía:

"No era lo que la profe precisamente quería. Yo, acostumbrada a separar cada materia, pensé en "la ruleta" solo para matemáticas y el juego del "ahorcado" solo para lenguaje, siendo que en esta escuela no es así, los/as niños/as aprenden de todo un poco al mismo tiempo. Había olvidado eso por completo, solo me dediqué a que quedaran bien los juegos para cada asignatura, las materias las separé, los/as estudiantes se iban a aburrir. Además, estarían toda la clase solo respondiendo a mis preguntas... ¿y dónde quedarían sus emociones? Lo había olvidado por completo".

Su profesora guía le muestra que las/os niñas/os están primero y le insta a interrogarse por el modo en que estarán presentes, a sentirlos, a distanciarse de la experiencia aprendida donde la enseñanza se hace por partes. $Y$, sí, pueden aprender de todo un poco al mismo tiempo y se abre una nueva dimensión: la de entretejer los saberes para disponerlos en el devenir de la clase, donde escuchar, sentir y hacer partícipe al otro/a con sus emociones es central para aprender. Yadhira vuelve a intentarlo.

"Trabajamos lo que es implícito y explícito, ambiente físico y psicológico, luego de ello les pedí que le cambiaran el nombre al personaje, también que con plastilina realizarán un dibujo $3 \mathrm{D}$ del personaje que más le gustó. ¡Estaban todos tan contentos... fue tan satisfactorio! Cada personaje quedó muy bello, a todos les gustó esta actividad. Todos y todas quedaron muy felices. Los niños y niñas se divirtieron demasiado, a más de alguno se le iba el internet, pero yo estaba super pendiente para repetir las preguntas o responder dudas."

La idea es que disfrutaran y leyeran en clases. Comentaran oralmente los problemas que enfrentan los personajes, lo que sentirían ellos si estuviesen en su lugar y describen los diferentes ambientes que aparecen. Pero Yadhira también busca que amplíen su capacidad expresiva desplazándose hacia lo estético, dando vida con la plastilina a una clase que, más que lejana, fría y fragmentada, se amasa en la plasticidad de la pregunta por los otros, por su presencia y participación, sin olvidar el estado emocional de estas "otras personas". La atmósfera importa, son niños/as de 10 años. La profesora guía y los/as niños/as son sus otras personas, aquellas que la llevan a perder el miedo, a reconectar con los caminos que había imaginado y a entrar de nuevo en el juego que había soñado de niña.

\subsection{Caracterizando personajes: cuestión de ubicación}

"Clases en línea" le hacen pensar en palabras como "frialdad, distancia (...) poco tiempo para cada asignatura". Gabriela está realizando una práctica profesional diferente a lo que siempre imaginó. Le preocupa el modo en que la estrechez del tiempo determinará la relación educativa. Sin embargo, de cuando en cuando, han tenido lugar las anheladas conversaciones, los encuentros entre ella y sus alumnos.

Un día recuerda:

"En una de las clases de Lengua y Literatura, específicamente trabajando la unidad de género dramático, los alumnos debian caracterizar tanto de forma directa e indirecta a los personajes involucrados dentro del fragmento "Cuestión de Ubicación", de Juan Radrigán".

El fragmento muestra una familia popular del Chile de los años 80 que, obsesionada por la adquisición de un enorme televisor, posterga la salud de una de sus hijas. Preocupados por dónde ubicar el aparato en la pequeña vivienda, la hija se agrava. El aparentar tener más y ser mejor que el vecino parece importar más.

A los personajes de una obra se les pueden analizar a través de los diálogos, acciones y acotaciones, de lo que dicen y de lo que se dice de ellos, de lo que los motiva, hacen y piensan. Y ese era el propósito de la clase, sin embargo, luego de la lectura, los alumnos comenzaron a comentar la parte del diálogo entre hermanos y en el chat aparecieron de pronto comentarios como: "Me imagino a la hermana con un buzo Adidas de la feria, pirata, medio flaite", "Seguramente se llama Kimberly", "Seguramente usa labial rojo y tiene un delineado corrido".

No cabe duda de que están caracterizando a los personajes. Pero, ¿desde dónde? Según el Diccionario de uso del español de Chile, 'flaite' es una "persona de clase social baja y comportamiento extravagante, que es relacionada generalmente con el 
mundo delictual". Asimismo, el nombre 'Kimberly' despierta discriminación asociada al estrato social.

Gabriela y su profesora esperaban que los alumnos comentaran el fragmento, relacionándolo con el contexto social, político e histórico de la obra, pero los comentarios les sacan de ese tiempo. Arrastradas a regresar al presente, al aquí y el ahora, “detienen" la caracterización.

La profesora preguntó: “¿Consideran correcto utilizar el término "flaite" solo por la condición económica de una familia?" E inmediatamente los alumnos comenzaron a corregirse entre sí: "Varios manifestaron que habían sido criados así y que por otro lado ellos igual sufren el temor de mostrarse como en realidad quieren, solamente por temor al qué dirán", relata Gabriela.

Pienso en la expresión "han sido criados así", en el encuentro generacional entre lo viejo y lo nuevo, en aquello que pervive sin más. $\mathrm{Y}$ es verdad: no comenzamos con las manos vacías y heredamos un "mundo interpretado". Habitamos costumbres (Sloterdijk, 2012) y, en nuestro relato, alumnos reproducen una lógica moral que sostiene que hay "seres" que deben ser alabados y tomados como modelos y otros "seres" que no y que tienen que ser descalificados (Mèlich, 2014).

Se acerca el final de la clase. El "mundo interpretado" no opera sin la complicidad de sus actores y sienten que no pueden interrumpir. En la aridez de intercambios virtuales ha ocurrido algo. Ambas consideraron que el tema debía seguir tratándose en la siguiente clase de Orientación que tenían con el mismo curso. Dirá Gabriela:

"Les hablé a los alumnos de las cosas que me gustan hacer y cómo he ido trabajando para sentirme segura de mí misma (...) que no existe una relación directa entre mis gustos y mi valor como persona (...) los invité a que se apropiaran de sus preferencias, ya sea, forma de vestir, estilo musical, entre otras (...)"

\section{Y, finalmente, dice Gabriela:}

"les mencioné que como generación pueden hacer el cambio y derribar los prejuicios que existen socialmente y que tanto nos dividen".

Pienso que, quizás, Gabriela interpretó que la aprensión de mostrarse como en realidad quieren es reflejo del miedo a sentirse en el otro lado del modelo, del temor a sentirse vulnerables y heridos (vulnus, "herida"). Y me pregunto si, quizás, una burla no sea sino una respuesta automática que, más que revelar quienes son este par de alumnos y lo que piensan, deja entrever las costumbres de un Chile que hoy está en crisis.

Enseñar quiere decir "poner algo sobre la mesa" (Simons y Masschelein, 2018; Skliar, 2017), y sus palabras hacen resonar una discriminación social que ha sido clave en el conflicto que se viene arrastrando desde octubre del 2019 y que, precisamente, viene movilizado por la joven generación:

“(...) muchos manifestaron que se habian emocionado con mis palabras, (...) que entendían muy bien mi punto de vista, además de compartirlo (...) se comprometieron a ser más conscientes al momento de emitir una opinión o apreciación respecto a otra persona, con el fin de evitar ampliar esta tendencia social de describir a los demás bajo una mirada prejuiciosa y marginadora".

En fin, al no estar hecha de pura comprensión intelectual, "la toma de consciencia no es enseñable, se da o no se da (...) Es un desplazamiento de mirada, de pensamiento, de actitudes prácticas, en síntesis, de ubicación simbólica" (Cosentino, 1996, p. 194). O sea, es una cuestión de ubicación.
Aparentemente el objetivo de la clase se había interrumpido. Al menos, eso pensé mientras recordaba una y otra vez esta experiencia, aunque quizás fue más bien el tiempo de responder a la necesidad de reubicar el lugar de la materia, reinstalando el objetivo de la clase en los mismos alumnos y sus vidas (no tan solo en una obra literaria y sus personajes). ¿Acaso los nuevos "personajes" a caracterizar no fueron los propios alumnos con su "mundo interpretado" y sus costumbres, la nueva "materia" puesta sobre la mesa? La materia salió más allá de la asignatura o entró la vida a metamorfosear su sentido... De cualquier modo, siento que comprendieron mejor la obra.

\section{Cierre}

La pandemia provocada por COVID-19 ha transformado el mundo y la manera de educar. En el mejor de los casos, las pantallas fueron dejando atrás la imagen tradicional de un aula habitada por maestros/as y alumnos/as. Frente al llamado a transmitir por la vía más corta los contenidos prioritarios y, quizás, empujados por las pantallas oscuras y micrófonos silenciados, hemos revalorizado más que nunca la presencia del otro, la otra, para que la relación educativa no se ahogue en la incomunicación. Y aunque lo educativo no se ha podido dar igual que siempre, $\mathrm{y}$ experimentamos tensiones diarias intentando mantener a salvo la labor educativa y reaccionamos con estupor ante descarnados testimonios de profesores/as, alumnos/as y familias, nos es difícil imaginar que, por muy árida que se vuelvan la enseñanza o por muy incomunicada que se torne la hora de la clase, no aparezcan en el camino los/as alumnos/as, ni salgan al encuentro las/os profesoras/es encendiéndose de tanto en tanto el acto educativo.

Con los relatos nos hemos introducido en el interior de esta virtualidad, en los destellos de las relaciones educativas, preguntándonos qué sucede cuando ocurre el encuentro educativo o qué tiene que acontecer para que se dé. Las experiencias relatadas nos permiten captar que algo pasa cuando las/os niñas/os se asoman y aparecen con sus voces y rostros, sus deseos y mundos, para desafiar el tiempo lineal de lo programado; cuando sus singularidades entran al aula virtual para conectar con la materia y empujarla a reconectar con la vida que hay más allá de la clase; cuando los contenidos se abren a relaciones con otras materias para romper la estrechez disciplinar y adherir a las vidas de los alumnos y alumnas; o cuando los conocimientos disciplinares se encuentran con los saberes experienciales, poblándose la clase de nuevas voces que hacen la enseñanza más significativa.

Las profesoras "han puesto algo sobre la mesa" para que algo pase, y los/as alumna/os se han asomado, alterando con su presencia el ritmo de las cosas o el curso de la clase. Y aunque siempre se pueda reconducir lo que irrumpe al plan previsto y retomar la secuencia programada, el deseo de relación o encuentro - hoy más que nunca - hace detener el tiempo, se abre a la espera y agudiza la atención para acoger a las otras y otros con sus vidas, para que la experiencia educativa se aproxime a lo vivo y perviva el deseo de aprender y de enseñar. Con inteligencia ordenadora, o con inteligencia amorosa (Piussi, 2006), las profesoras han sabido ir a lo profundo del ser para volver a poner en movimiento el flujo de la vida, para abrir espacios nuevos y hacer sitio a relaciones donde había desconexión, reubicando las materias junto a los mundos de los alumnos/as, para que algo suceda, para que la vida se haga presente y se encienda nuevamente el acto educativo.

\section{Referencias}

Arnaus, R. y Piussi, A. M. (2010). Universidad fértil. Octaedro. 
Bárcena, F. (2012). Una pedagogía de la presencia. Crítica filosófica a la impostura pedagógica. Teoría de la Educación. Revista Interuniversitaria, 24(2), 25-57. https://doi.org/10.14201/10354

Bárcena, F. y Mèlich, J. C. (2000). La educación como acontecimiento ético. Paidós.

Biesta, G. J. J. (2020). Have we been paying attention? Educational anaesthetics in a time of crises. Educational Philosophy and Theory. https://doi.org/10.1080/00131857.2020.1792612

Clandinin, D. J. y Connelly, F. M. (2000). Narrative Inquiry. Experience and Story in Qualitative Research. Jossey-Bass.

Clandinin, J. (2013). Engaging in Narrative Inquiry. Routledge.

Contreras, J. (2016a). Tensiones fructíferas. Octaedro.

Contreras, J. (2016b). Tener historias que contar: profundizar narrativamente la educación. Roteiro, Joaçaba, 41(1), 15-40. https://doi.org/10.18593/r.v41i1.9259

Contreras, J. (2017). Enseñar tejiendo relaciones. Morata.

Contreras, J., Quiles-Fernández, E. y Paredes, A. (2019). Una pedagogía narrativa para la formación del profesorado. Márgenes, Revista de Educación de la Universidad de Málaga, 0(0), 58-75. https://doi.org/10.24310/mgnmar.v0i0.6624

Cosentino, V. (1996). Hacer práctica, interrogar a la práctica. En A. M. Piussi y L. Bianchi (Eds.), Saber que se sabe (pp. 187-204). Icaria.

Di Bartolomeo, M. (1998). Il tempo regolamentato. En A. Lelario, V. Cosentino y G. Armellini (Eds.), Buone notizie dalla scuola (pp. 95-98). Pratiche Editrice.

Duschatzky, L. (2019). ¿Cómo disfrutar mis clases? Morata.

Dussel, I. (2018). Sobre la precariedad de la escuela. En J. Larrosa (Ed.), Elogio de la escuela (pp. 83-106). Miño y Dávila.

Dussel, I. (2020). La escuela en la pandemia. Reflexiones sobre lo escolar en tiempos dislocados. Práxis Educativa, 15, 1-16. https://doi.org/10.5212/PraxEduc.v.15.16482.090

Flores, M. A. y Swennen, A. (2020). The COVID-19 pandemic and its effects on teacher education. European Journal of Teacher Education, 43(4), 453-456. https://doi.org/10.1080/0261976 8.2020.1824253

González-Calvo, G. (2020). Vivo y enseñando, pero... ¿por cuánto tiempo? Cuando las circunstancias sociales y los tiempos de pandemia convierten la pasión por la enseñanza en duda y desánimo. Márgenes, Revista de Educación de la Universidad de Málaga, 1(3), 110-132. https://doi.org/10.24310/mgnmar. v1i3.8714

Han, B. C. (2017). La expulsión de lo distinto. Herder.

Hargreaves, A. (2021). Austerity and inequality; or prosperity for all? Educational policy directions beyond the pandemic. Educational Research for Policy and Practice, 20, 3-10. https:// doi.org/10.1007/s10671-020-09283-5
Hormazábal, R. (2016). La historia que nos nace. Indagación narrativa con docentes en la experiencia de enseñar historia en Bachillerato [Tesis doctoral]. Universidad de Barcelona, España. https:// www.tdx.cat/handle/10803/393950

Larrosa, J. (2018). Elogio de la escuela. Miño y Dávila.

Masschelein, J. y Simons, M. (2014). La defensa de la escuela. Miño y Dávila.

Meirieu, P. (2016). Recuperar la pedagogía. De lugares comunes a conceptos claves. Paidós.

Mèlich, J. (2014). Lógica de la crueldad. Herder.

Piussi, A. M. (2006). El sentido libre de la diferencia sexual en la educación. En A. M. Piussi y A. Mañeru, Educación nombre común femenino (pp. 15-35). Octaedro.

Quiles-Fernández, E. y Orozco Martínez, S. (2019). Atender las tensiones educativas en la formación inicial del profesorado: La Indagación Narrativa como práctica pedagógica. Revista interuniversitaria de Formación del Profesorado, 94 (33.3), 105120. https://doi.org/10.47553/rifop.v33i3.75231

Quiles-Fernández, E., Hizmeri, J. y Hormazábal-Fajardo, R. (2018). Formarse en la investigación educativa: una comunidad de pensamiento en torno a la escritura de la tesis doctoral. Qualitative Research in Education, 7(3), 241-264. http:// dx.doi.org/10.17583/qre.2018.3482

Rancière, J. (2010). El espectador emancipado. Manantial.

Ruiz, G. R. (2020). The Pandemic Traces: The Stricken Right to Education. Revista Internacional de Educación para la Justicia Social, 9(3), 45-59. https://doi.org/10.15366/riejs2020.9.3.003

Silva-Peña, I. (2020). Mantener los vínculos: pedagogía de emergencia en tiempos de coronavirus. En https://www.elmostrador.cl/agenda-pais/2020/04/19/mantener-los-vinculos-pedagogia-de-emergencia-en-tiempos-de-coronavirus/

Simons, M. y Masschelein, M. (2018). Experiencias escolares: intentando encontrar una voz pedagógica. En J. Larrosa (Ed.), Elogio de la escuela (pp. 41- 62). Miño y Dávila.

Skliar, C. (2017). Pedagogías de las diferencias. Noveduc.

Sloterdijk, P. (2012). Has de cambiar tu vida: Sobre antropotécnica. Pre-textos

Van Manen, M. (2003). Investigación educativa y experiencia vivida. Idea Books.

Van Manen, M. (2014). Phenomenology of Practice. Left Coast Press.

Williamson, B., Enyon, R. y Potter, J. (2020). Pandemic politics, pedagogies and practices: digital technologies and distance education during the coronavirus emergency. Learning, Media and Technology, 45(2), 107-114. https://doi.org/10.1080/174 39884.2020.1761641

Zambrano, M. (2012). Hacia un saber sobre el alma. Alianza literaria. 
